\title{
Characteristics Study of Photovoltaic Thermal System with Emphasis on Energy Efficiency
}

\author{
Chuah Yee Yong ${ }^{l}$, Mohammad Taghi Hajibeigy ${ }^{l, *}$, Chockalingam Aravind Vaithilingam ${ }^{l}$, \\ Rashmi Gangasa Walvekar ${ }^{l}$ \\ ${ }^{1}$ Taylor's University Lakeside Campus, Subang Jaya, Selangor, Malaysia
}

\begin{abstract}
Solar energy is typically collected through photovoltaic (PV) to generate electricity or through thermal collectors as heat energy, they are generally utilised separately. This project is done with the purpose of integrating the two systems to improve the energy efficiency. The idea of this photovoltaic-thermal (PVT) setup design is to simultaneously cool the PV panel so it can operate at a lower temperature thus higher electrical efficiency and also store the thermal energy. The experimental data shows that the PVT setup increased the electrical efficiency of the standard PV setup from $1.64 \%$ to $2.15 \%$. The integration of the thermal collector also allowed $37.25 \%$ of solar energy to be stored as thermal energy. The standard PV setup harnessed only $1.64 \%$ of the solar energy, whereas the PVT setup achieved $39.4 \%$. Different flowrates were tested to determine its effects on the PVT setup's electrical and thermal efficiency. The various flowrate does not significantly impact the electrical efficiency since it did not significantly impact the cooling of the panel. The various flowrates resulted in fluctuating thermal efficiencies, the relation between the two is inconclusive in this project.
\end{abstract}

\section{Introduction}

Current world energy demand is largely fulfilled by fossil fuel. Fossil fuel has the advantages over renewable energy that it is well documented and has the much more developed technology to harness the energy it provides. However, there are many reasons for us to move on to renewable energies such as solar, wind, geothermal and so on. Conventional coal-fired plants are the top generator all around the world but the process comes with large amounts of greenhouse gases and is unsustainable with the sources depleting. Figure 1 below shows the 2016 statistics of power generation and the methods used.

\footnotetext{
*Corresponding author: MohammadTaghi.Hajibeigy@Taylors.edu.my
} 


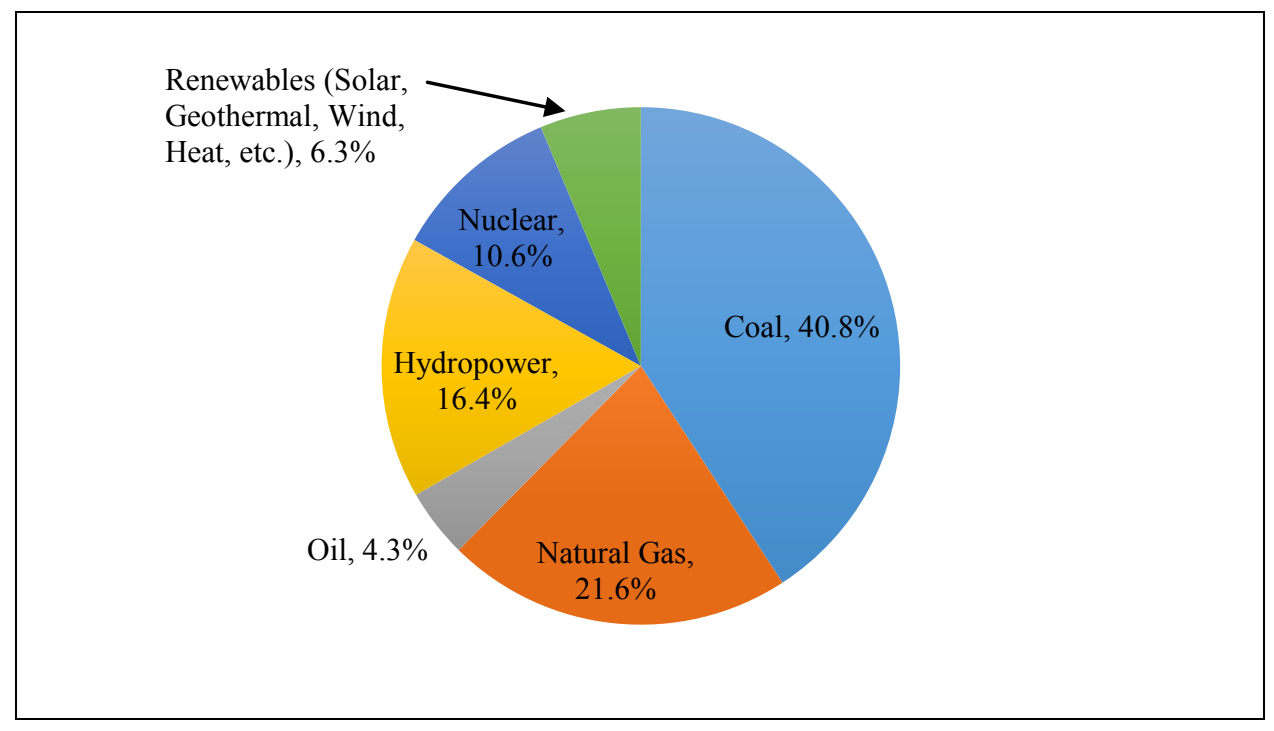

Fig. 1: Sources of Global Electricity Generation [1].

With cutting down the usage of fossil fuel to generate power as a target, this project approaches it through attempting to improve current methods of harnessing solar energy. Present methods of collecting solar energy fall into two categories, photovoltaic (PV) and thermal energy. Photovoltaics uses semiconductor materials which are capable of converting light into electricity, whereas thermal collectors are self-explanatory, where a collector is used to collect heat radiated from the light source.

Only a small amount of the solar energy can be harnessed by the PV panels, which are due to factors such as the current limitations of the technology. Standard monocrystalline panels can operate at roughly $15 \%-20 \%$ efficiency where the remaining solar energy is converted into thermal energy and are wasted. Currently, there are efforts to improve efficiency through methods such as solar tracking where the solar panels are designed to tilt itself towards the direction of the sun, such as passive and active orientation systems [2].

Where the tracking method improves electrical energy through adjusting the angle the sunlight hits the panel, the methods discussed in [3-8] uses the approach of reducing the temperature of the solar panel where high operating temperature causes a reduction in the panels' efficiency. Cooling the solar panel using several fluids were done by [3-6], whereas [7] shows that Phase Change Materials (PCM) can be considered to maintain the low temperature of the solar panel and [8] cools the solar panel by directly spraying water onto the panel surface.

The proposed method to increase solar energy harnessed is to retrofit a thermal system to a standard monocrystalline panel, where the integrated system is expected to operate at a higher efficiency. The design is to attach a heat sink to the back of the solar 
panel with thermal compound in between to allow heat to transfer from the panel to the heat sink. It is shown that Thermal Interface Materials (TIM) are essential to two contacting surfaces regarding heat transfer, where two flat surfaces can seemingly be tightly contacting while having microscopic air gaps that negatively affects the efficiency of heat transfer $[9,10]$. The heat sink is submerged into a body of water where it transfers the heat to a water storage tank through a copper tube. The idea of this design is to simultaneously cool the panel, which improves operating efficiency and harness the thermal energy.

\section{Methodology}

\subsection{Setup Design and Fabrication}

Solar panels generally are sold in the market without any heat dissipation modifications, where the panels are usually installed individually. That meant the fabrication of heat sinks to suitable specifications are required, SEMS Sdn. Bhd. agreed to arrange a heat sink in the desired dimensions. Due to a limited budget, it is not viable to fabricate a custom heatsink from scratch. Figure 2 shows the solar panel with the heat sink attached to the underside of the monocrystalline panel.

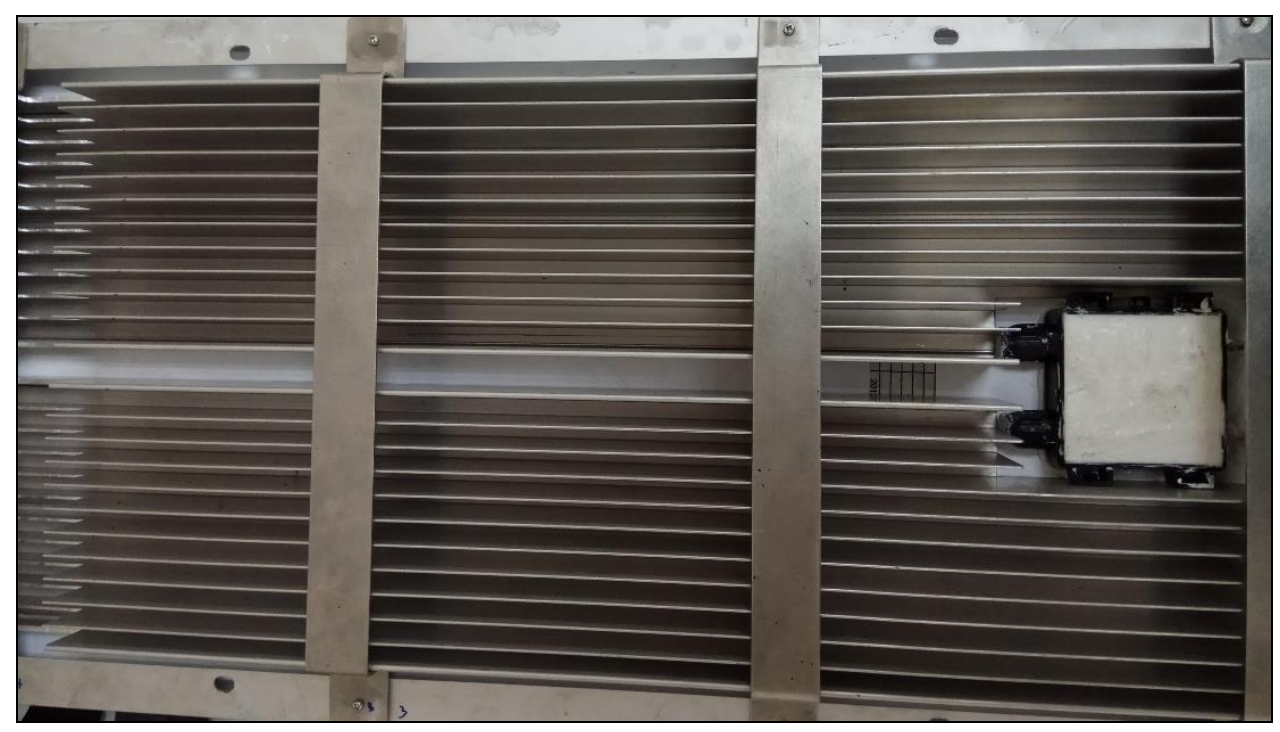

Fig. 2. PVT Panel Setup.

To avoid short circuit of the wirings, the wiring housing is sealed with silicone glue which is waterproof. The space between the panel and the heat sink are filled with thermal compound Kafuter K-5211, that prevents air pockets which reduces the effectiveness of heat transfer between the two layers. 


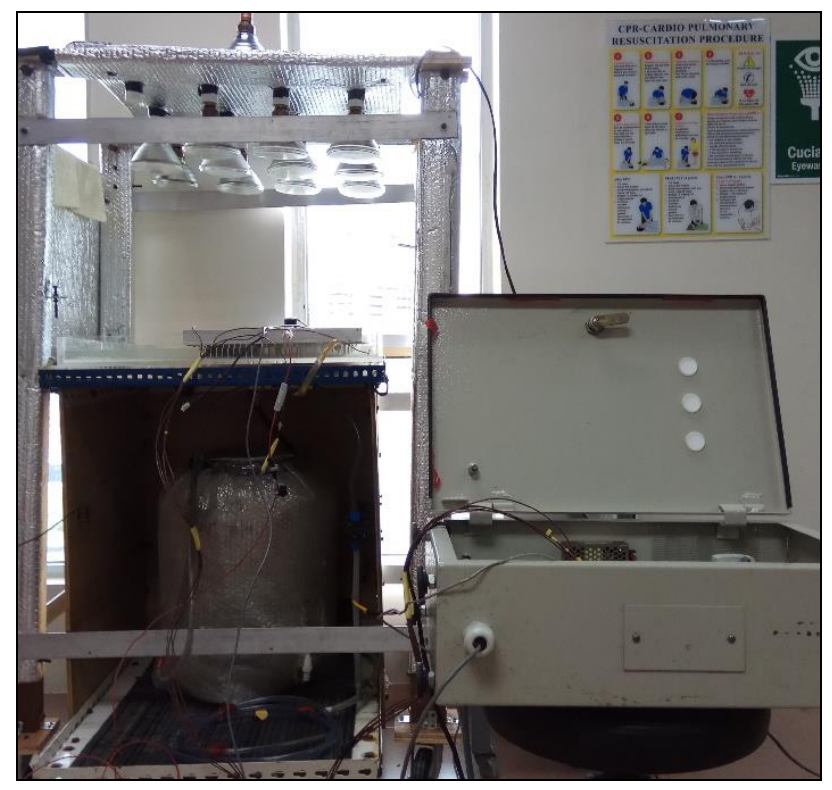

Fig. 3. Overall Experimental Setup.

The experiment will be done indoors to keep factors such as ambient temperature, fluctuating solar energy as consistent as possible. The overall setup can be seen in Figure 3 above, where the lightbulbs are placed directly above the panel that is used to provide consistent light energy. The heat sink is submerged in water within a Perspex container that has water being cycled through a water storage tank. The container on the right of the water storage tank holds the electronics such as the pyranometer and the data-logger.

\subsection{Experimental Procedures}

The steps below were taken to obtain the electrical and thermal performance:

i. Adjust the power supplied to the water pump at $12 \mathrm{~V}$.

ii. Switch on the lights.

iii. Start the data-logger.

iv. Start the EpSolar Monitoring Software.

v. Allow the setup to continue for 10 minutes.

vi. Collect data and switch off the water pump and lights.

vii. Experiment is repeated at different water pump power supply after water storage tank return to ambient temperature.

The panel temperature is observed throughout the experiment to ensure it does not exceed $70^{\circ} \mathrm{C}$ as it can cause permanent damage to the panel which reduces its operating efficiency.

\subsection{Electrical Efficiency}

The electrical efficiency of the solar panel was calculated using the equation below: 


$$
\eta_{\text {elec }}=\left(V_{m} I_{m}\right) / A R
$$

Where: $\quad \eta_{\text {elec }}=$ electrical efficiency

$\mathrm{V}_{\mathrm{m}}=$ maximum power point voltage, $\mathrm{V}$

$\mathrm{I}_{\mathrm{m}} \quad=$ maximum power point current, $\mathrm{A}$

$\mathrm{A}=$ panel area, $\mathrm{m}^{2}$

$\mathrm{R}=$ solar radiation, $\mathrm{W} / \mathrm{m} 2$

\subsection{Thermal Efficiency}

At steady state, the PVT thermal performance can be calculated using the equation below:

$$
\eta_{T}=(\text { thermal energy collected }) /(\text { total amount of solar energy) }
$$

$$
\eta_{T}=\left(m C_{p}\left(T_{o}-T_{i}\right)\right) / A R t
$$

Where: $\quad \eta_{\mathrm{T}} \quad=$ thermal efficiency

$\mathrm{m}=$ water mass, $\mathrm{kg}$

$\mathrm{C}_{\mathrm{p}} \quad=$ specific heat capacity, $\mathrm{kJ} / \mathrm{kg} . \mathrm{K}$

$\mathrm{T}_{\mathrm{o}} \quad=$ outlet temperature, $\mathrm{K}$

$\mathrm{T}_{\mathrm{i}} \quad=$ inlet temperature, $\mathrm{K}$

$\mathrm{t}=$ time, $\mathrm{s}$

\section{Results}

\subsection{Electrical Efficiency}

\subsubsection{Difference in Standard PV and PVT Setup}

The difference between a standard monocrystalline PV setup and the novel PVT setup fabricated for this project is observed. The factors for both setups such as ambient temperature, distance of panel to light bulbs and more are kept as consistent as possible. The power generated is recorded using the EpSolar Monitoring Software. Figure 4 below shows the irradiance and the power generated by the PV setup throughout the experiment. At the peak of the power generated by the solar panel, the PV setup achieved a $3.77 \%$ electrical efficiency. This setup recorded an average efficiency of $1.64 \%$. 


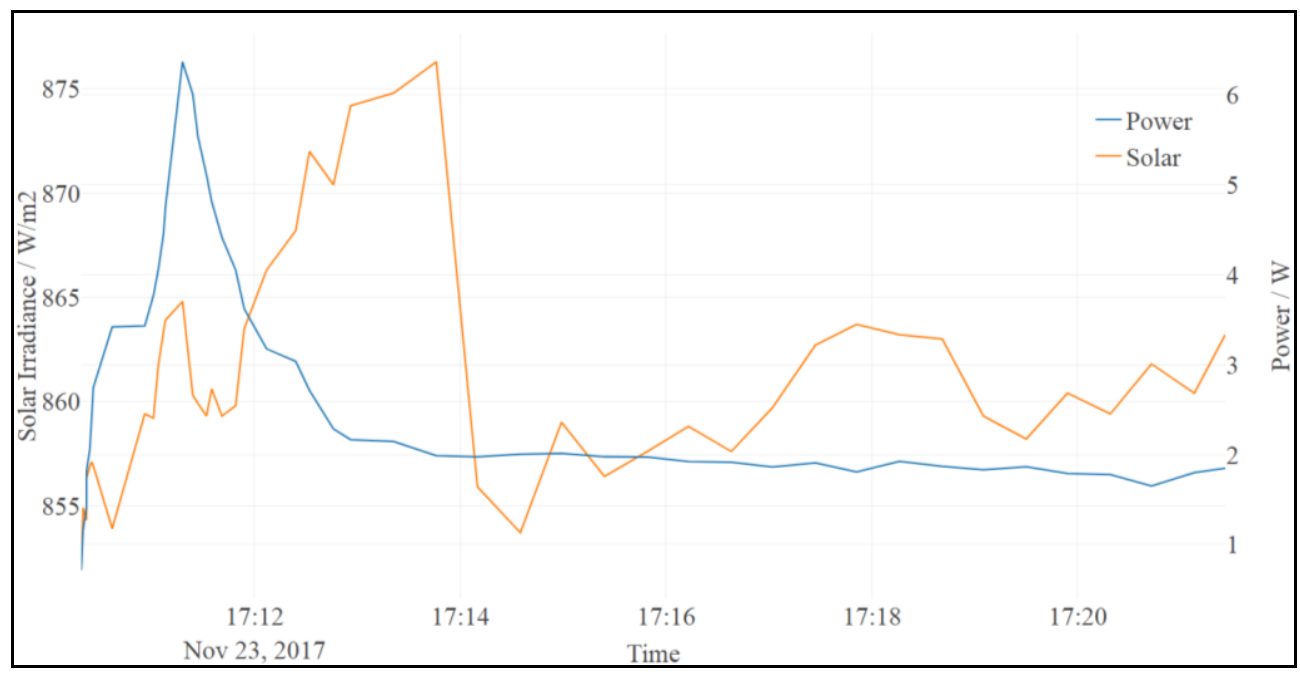

Fig. 4. Real Time Power Graph of PV Panel.

Figure 5 below shows the results of the PVT setup, with the water pump running at 8.4 $\mathrm{L} / \mathrm{min}$. It is measured at $4.62 \%$ maximum electrical efficiency and $2.15 \%$ average electrical efficiency.

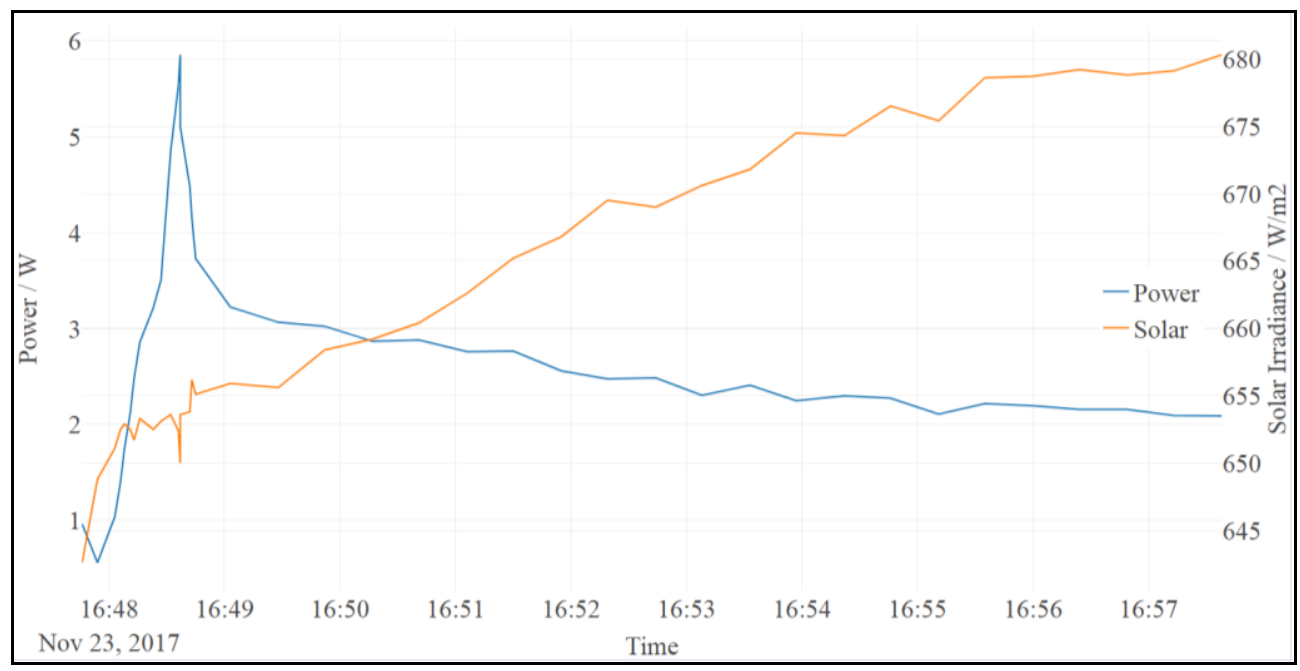

Fig. 5. Real Time Power Graph of PVT Setup.

\subsubsection{Difference in Flowrate of PVT Setup}

By using an adjustable $\mathrm{AC} / \mathrm{DC}$ converter, the flowrate flowing into the Perspex container is set to $3.9 \mathrm{~L} / \mathrm{min}, 5.3 \mathrm{~L} / \mathrm{min}, 6.4 \mathrm{~L} / \mathrm{min}$ and $8.4 \mathrm{~L} / \mathrm{min}$. The flowrates are respectively due to the voltage fed to the water pump being $6 \mathrm{~V}, 7.5 \mathrm{~V}, 9 \mathrm{~V}$ and $12 \mathrm{~V}$. 
Table 1. Water Pump Flow Rate at the Corresponding Voltages.

\begin{tabular}{|c|c|}
\hline Voltage Supplied (V) & Flowrate (L/min) \\
\hline 6.0 & 3.9 \\
\hline 7.5 & 5.3 \\
\hline 9.0 & 6.4 \\
\hline 12.0 & 8.4 \\
\hline
\end{tabular}

The electrical power generated between the four experiments are recorded and graphed together to be compared in Figure 6 below.

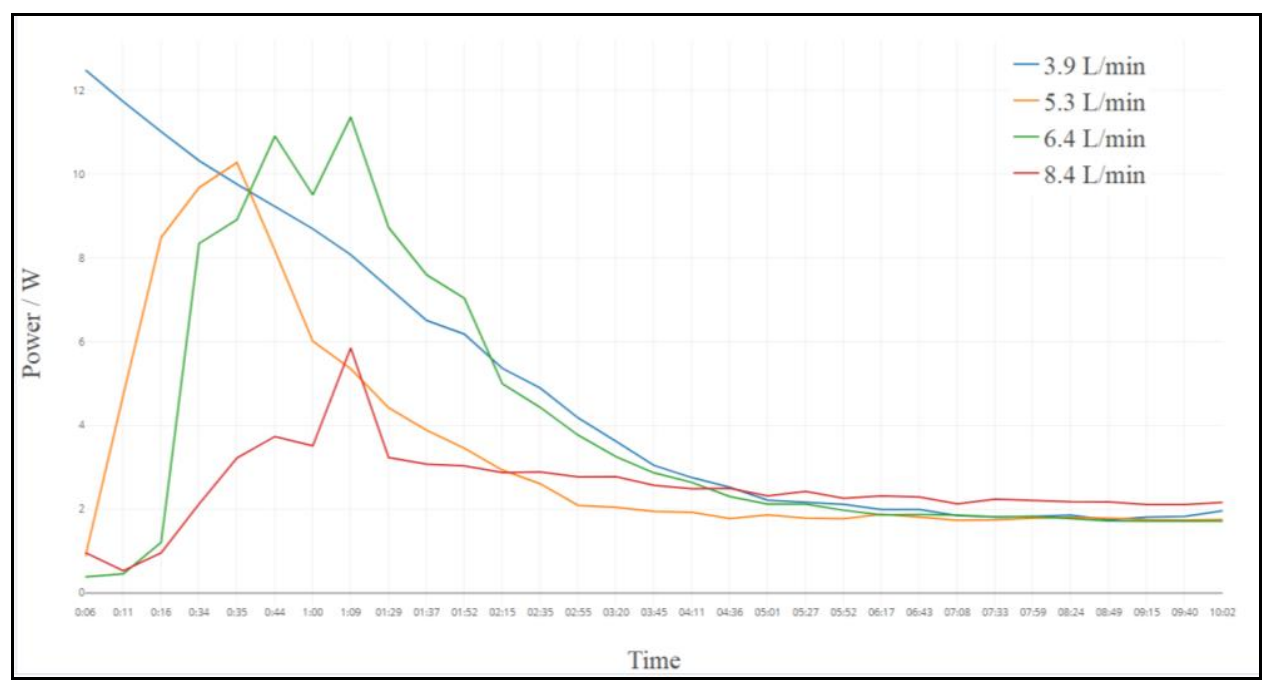

Fig. 6. Real Time Power Graph at Different Flow Rates.

\subsection{Thermal Efficiency}

The same experimental procedures are used to determine the thermal performance of the PVT setup. The temperature of the water in the storage tank is recorded and the difference between the beginning and the end of the experiment is tabulated as below. 
Table 2. The Difference of Water Temperature.

\begin{tabular}{|c|c|}
\hline Water Flowrate & Temperature Difference $\left({ }^{\circ} \mathbf{C}\right)$ \\
\hline $3.9 \mathrm{~L} / \mathrm{min}$ & 1.9 \\
\hline $5.3 \mathrm{~L} / \mathrm{min}$ & 1.1 \\
\hline $6.4 \mathrm{~L} / \mathrm{min}$ & 2.3 \\
\hline $8.4 \mathrm{~L} / \mathrm{min}$ & 1.4 \\
\hline
\end{tabular}

By using the formulae mentioned in subsection 2.4, the thermal efficiency of the setup can be calculated. The heat capacity of water is assumed to be at $4184 \mathrm{~J} / \mathrm{kgK}$. Table 3 below shows the resulting thermal efficiency of the PVT setup at various flowrates.

Table 3. Different Flowrates and the Corresponding Thermal Performance.

\begin{tabular}{|c|c|c|c|}
\hline Experiment & Water Flowrate & Average Irradiance & Thermal Efficiency \\
\hline 1 & $3.9 \mathrm{~L} / \mathrm{min}$ & 704.10 & $48.25 \%$ \\
\hline 2 & $5.3 \mathrm{~L} / \mathrm{min}$ & 705.57 & $27.88 \%$ \\
\hline 3 & $6.4 \mathrm{~L} / \mathrm{min}$ & 715.77 & $57.46 \%$ \\
\hline 4 & $8.4 \mathrm{~L} / \mathrm{min}$ & 672.01 & $37.25 \%$ \\
\hline
\end{tabular}

\subsection{Combined Efficiency}

The combined efficiency of the standard PV setup and the fabricated PVT setup are compared. Combined efficiency refers to the sum of both thermal efficiency and the electrical efficiency. It is used to compare whether the integration of thermal collector to the standard PV panel will yield an improvement in harnessing solar energy.

The combined efficiency of the PVT system resulted in $39.4 \%$ efficiency while the standard PV setup can only harness electrical energy, thus only operates at $1.64 \%$ efficiency in harnessing solar energy.

\section{Conclusion}

The integration of a thermal system which simultaneously cools the panel and collects thermal energy allowed the solar panel to operate at a higher efficiency. The standard PV setup is rated at $1.64 \%$ electrical efficiency while the PVT setup is rated at $2.15 \%$. The decreasing power generated over time can be attributed to the increasing temperature of the 
panel, illustrated in Figure 7 below where the PVT setup is shown dissipating heat better than the standard PV setup.

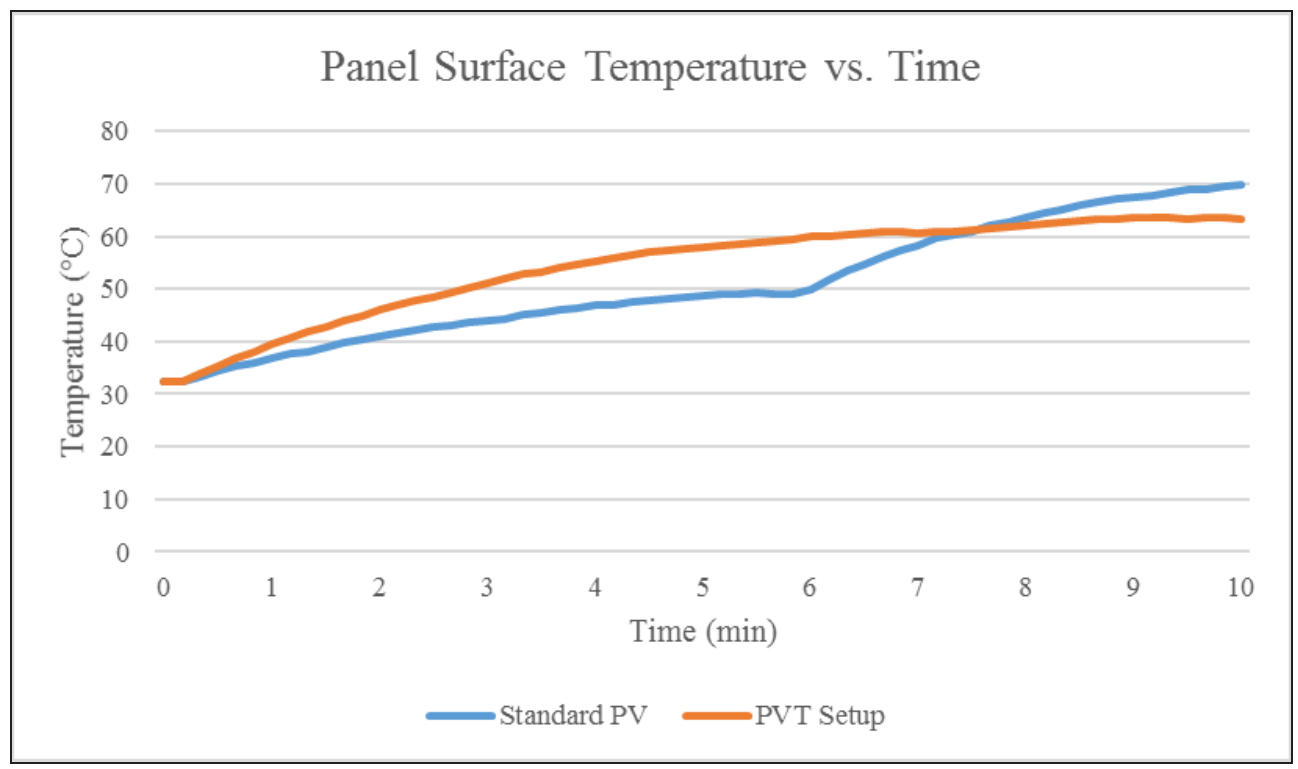

Fig. 7. The temperature of PV Panel Surface over Time.

The PVT setup boasts a much improved combined efficiency in harnessing solar energy, from $1.64 \%$ to $39.4 \%$ of solar energy collected which deems that integration of thermal system to an existing PV setup successful in terms of improving energy efficiency.

The effects on how the flowrate affect the electrical efficiency and thermal efficiency are also studied in this project. It seems that the flow rate does not significantly impact the electrical efficiency, whereas the thermal efficiency of the PVT setup fluctuates and the relationship between the two could not be defined.

However, it should be noted that the solar panels provided could be unreliable as typical monocrystalline panels operate at roughly $15 \%$ efficiency, while the panels used only operated around $2 \%$.

\section{References}

1. International Energy Agency, "Key world energy statistics," Statistics (Ber)., p. 80, (2016)

2. I. L. Alboteanu, F. Ravigan, and S. Degeratu, "Methods for Increasing Energy Efficiency of Photovoltaic Systems," Int. J. Power Renew. Energy Syst., vol. 1, pp. 51$61(2014)$

3. H. Bahaidarah, A. Subhan, P. Gandhidasan, and S. Rehman, "Performance evaluation of a PV (photovoltaic) module by back surface water cooling for hot climatic 
conditions," Energy, vol. 59, pp. 445-453 (2013)

4. R. Mazón-Hernández, J. R.García-Cascales, F. Vera-García, A. S. Káiser, and B. Zamora, "Improving the Electrical Parameters of a Photovoltaic Panel by Means of an Induced or Forced Air Stream" (2013)

5. J. K. Tonui and Y. Tripanagnostopoulos, "Air-cooled PV/T solar collectors with low cost performance improvements," Sol. Energy, vol. 81, no. 4, pp. 498-511 (2007)

6. C. G. Popovici, S. V. Hudişteanu, T. D. Mateescu, and N.-C. Cherecheş, "Efficiency Improvement of Photovoltaic Panels by Using Air Cooled Heat Sinks," Energy Procedia, vol. 85, no. November 2015, pp. 425-432 (2016)

7. A. Hasan, S. J. McCormack, M. J. Huang, and B. Norton, "Evaluation of phase change materials for thermal regulation enhancement of building integrated photovoltaics," Sol. Energy, vol. 84, no. 9, pp. 1601-1612 (2010)

8. K. A. Moharram, M. S. Abd-Elhady, H. A. Kandil, and H. El-Sherif, "Enhancing the performance of photovoltaic panels by water cooling," Ain Shams Eng. J., vol. 4, no. 4, pp. 869-877 (2013)

9. R. Prasher and C.-P. Chiu, "Thermal Interface Materials," in Materials for Advanced Packaging, D. Lu and C. P. Wong, Eds. Cham: Springer International Publishing, pp. 511-535 (2017)

10. D. L. Saums, “Advances in Thermal Interface Materials for Power LED Applications," in Thermal Management for LED Applications, C. J. M. Lasance and A. Poppe, Eds. New York, NY: Springer New York, pp. 299-346 (2014) 